\title{
LABOUR PRODUCTIVITY GROWTH SLOWDOWN: AN EFFECT OF ECONOMIC STAGNATION RATHER THAN ITS CAUSE?
}

\author{
Leon PODKAMINER
}

This paper reports the results of an econometric examination on the links between labour productivity and output growth for 22 countries (for which long-term data are available). It turns out that, generally, labour productivity does not "cause" output. In more cases, the causation seems to be running in the opposite direction: from output to productivity. This finding, though inconsistent with the "mainstream" ideas on the sources of long-term economic growth, is reminiscent of the classical Kaldor-Verdoorn Law. The progressing slowdown in output growth on the global level, initiated around the mid-1970s (when the process of discarding the earlier economic policy paradigms set in), may have been mirrored by the progressing slowdown in productivity growth (and that despite the hardly disputable acceleration of technological progress).

Keywords: labour productivity, economic growth, Kaldor-Verdoorn Law, Granger causality JEL classification indices: $\mathrm{O} 40, \mathrm{O} 49, \mathrm{O} 57$

Leon Podkaminer, Economist at the Vienna Institute for International Economic Studies, Austria. E-mail: podkaminer@wiiw.ac.at 
"The most important factor determining continued advances in living standards is productivity growth, defined as the rate of increase in how much a worker can produce in an hour of work. Over time, sustained increases in productivity are necessary to support rising household incomes."

Fed Chair Yellen (2015)

\section{INTRODUCTION}

There is no shortage of speculations about the factors responsible for secular stagnation. Such stagnation is believed to have engulfed the developed parts of the global economy. The view, rather commonly shared by the mainstream, is that the current stagnation set in around 2008, as the global financial crisis released forces that have since been preventing the resumption of fast economic growth allegedly characterising the earlier decades. ${ }^{1}$ The mainstream opinions do differ on many counts. But they seem to be sharing the belief that the "monetary factors" (e.g. pertaining to the "zero lower band") are at least co-responsible for the present (post-2008) predicament. Moreover, they all tend to emphasise the need for "difficult but uncontroversial reforms" (i.e. for further "structural reforms of the supply side") as the primary way of ending the stagnation. Robert Gordon (2015) may be the most vocal representative of the "supply-siders". He goes as far as to blame the post-2008 stagnation itself on the slower growth (since 2004) in potential output "emanating from the behavior of productivity".

This paper reports the results of an econometric examination on the links between labour productivity and output growth for 22 countries (for which longterm data are available), for West Germany (years 1960 through 1991), for unified Germany (years 1991-2015) and also for a larger set of countries (years 1991 or 1995, through 2015). It turns out that, generally, productivity does not "cause" output. Much more often, the causation seems to be running in the opposite direction: from output (or its growth rate) to productivity (or its growth rate). This finding, though inconsistent with the "mainstream" ideas on the sources of long-term economic growth, is reminiscent of the classical Kaldor-Verdoorn Law (Verdoorn 1949; Kaldor 1966; McCombie et al. 2002). The progressive slowdown in output growth on the global level, initiated in the mid-1970s (amid the wholesale change of economic policy paradigms), may have been mirrored by the progressive slowdown in productivity growth (and that despite the indisputable acceleration of technological progress).

1 See, e.g., the recent review of popular views by Canuto et al. (2014), or a more extensive presentation of the opinions held by the prominent representatives of "economic science", collected in a VOX volume edited by Teulings - Baldwin (2014). 


\section{THE DATA}

Eurostat's AMECO database reports longer-term time series (1960-2015) on per capita real GDP and real GDP per employed person (series RVGDP and RVGDE, respectively) for 22 countries: 14 "old" Member States (MSs) of the European Union, Switzerland, Norway, Turkey, the US, Japan, Canada, Australia, and New Zealand. Because of the "break" in the data due to the 1991 German Unification, there are two separate time series: for West Germany (1960-1991) and for unified Germany (1991-2015). The time series for the 10 "new" (East European) Member States (NMSs) of the European Union start in the first half of the 1990s.

The initial treatment of the series in question is fairly standard. In each case, the natural logarithms of the original series (denoted Y and P) are tested for stationarity. The KPSS tests reject stationarity, in most cases decisively, whether one includes intercept or trend with intercept. The ADF unit root tests support the KPSS results: the null hypothesis of unit root cannot be rejected in any individual case. The ADF unit roots test applied to the differenced series rejects the unit root hypothesis in each case, indicating that the series are very likely integrated of order 1 .

\section{A change in output Granger causes ${ }^{2}$ a change in labour productivity much more often than productivity Granger causes output}

As the series $\mathrm{Y}$ and $\mathrm{P}$ are likely to be integrated of order 1 and their first differences $(d(Y)$ and $d(P)$ respectively, ) are stationary, it makes sense to check whether or not d(P) Granger causes d(Y), and whether d(Y) Granger causes d(P).

2 Granger causality is understood as follows: Assume one considers two stationary time series $\mathrm{X}$ and $\mathrm{Z}$. $\mathrm{X}$ is said to Granger cause $\mathrm{Z}$ if $\mathrm{Z}$ can be better predicted using the histories of both $\mathrm{X}$ and $Z$ than it can by using the history of $Z$ alone. The same applies to $X$ being Granger caused by Z. Absence of Granger causality can be tested by estimating the Vector Autoregression (VAR) model with two equations:

$\mathrm{Z}_{\mathrm{t}}=\mathrm{a}_{0}+\mathrm{a}_{1} \mathrm{Z}_{\mathrm{t}-1}+\ldots+\mathrm{a}_{\mathrm{p}} \mathrm{Z}_{\mathrm{t}-\mathrm{p}}+\mathrm{b}_{1} \mathrm{X}_{\mathrm{t}-1}+\ldots+\mathrm{b}_{\mathrm{p}} \mathrm{X}_{\mathrm{t}-\mathrm{p}}+\mathrm{u}_{\mathrm{t}}$

$\mathrm{X}_{\mathrm{t}}=\mathrm{c}_{0}+\mathrm{c}_{1} \mathrm{Z}_{\mathrm{t}-1}+\ldots+\mathrm{c}_{\mathrm{p}} \mathrm{Z}_{\mathrm{t}-\mathrm{p}}+\mathrm{d}_{1} \mathrm{X}_{\mathrm{t}-1}+\ldots+\mathrm{d}_{\mathrm{p}} \mathrm{X}_{\mathrm{t}-\mathrm{p}}+\mathrm{v}_{\mathrm{t}}$

The parameters " $a$ " and " $b$ " remain to be estimated; $u$ and $v$ are error terms. $H_{0}: b_{1}=b_{2}=\ldots$ $b_{p}=0$ is a test that $X$ does not Granger cause $Z$. Similarly, $H_{0}: c_{1}=c_{2}=\ldots c_{p}=0$ is a test that $Z$ does not Granger cause $\mathrm{X}$. Testing $\mathrm{H}_{\mathrm{o}}$ is in terms of the usual Wald test statistics. The results may (and often do) depend on the number of lags (p) taken. That number can be selected on the basis of so-called information criteria (such as Schwartz's or Akaike) and paying attention to the additional properties of the VAR model (its stability and absence of residual autocorrelation). 


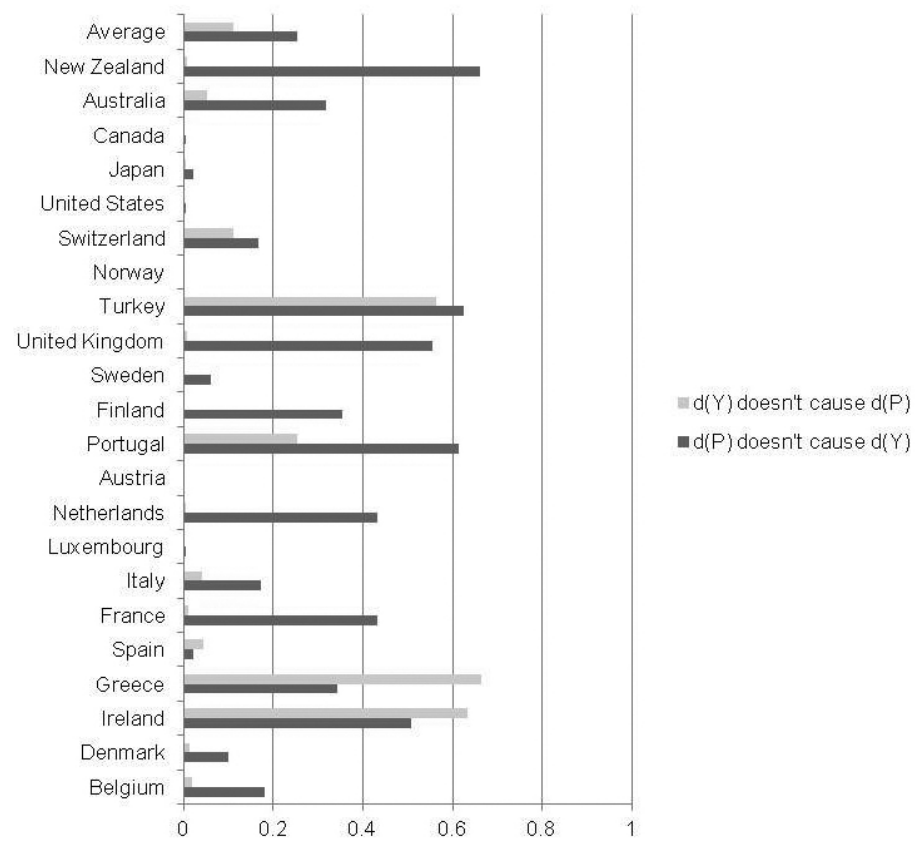

Figure 1. Probabilities of Granger non-causality (based on chi-sq stat.), 1960-2015

Figures 1 and 2 show the probabilities of Granger non-causality between $\mathrm{d}(\mathrm{Y})$ and $\mathrm{d}(\mathrm{P})^{3}$ for 22 countries. As can be seen, the probabilities of Granger non-causality are, on average, much higher for the hypothesis on $\mathrm{d}(\mathrm{P})$ affecting $\mathrm{d}(\mathrm{Y})$ than for the hypothesis on $\mathrm{d}(\mathrm{Y})$ affecting $\mathrm{d}(\mathrm{P})$. The hypothesis on $\mathrm{d}(\mathrm{P})$ not Granger causing $\mathrm{d}(\mathrm{Y})$ is rejected, at the $5 \%$ significance level, in 7 cases (while not allowing for eventual trends, see Figure 1). In these 7 cases, the statistical evidence is there on causality running from changes in productivity to changes in output. However, the hypothesis on $\mathrm{d}(\mathrm{Y})$ not Granger causing $\mathrm{d}(\mathrm{P})$ is rejected, at the $5 \%$ significance level, in 16 cases. In these 16 cases, the statistical evidence is there on causality running from changes in output to changes in productivity.

Observe that in 7 cases (Spain, Luxembourg, Austria, Norway, USA, Japan, Canada), the evidence is quite strong that the Granger causality runs in both

3 The probabilities were derived from auxiliary Vector Autoregression (VAR) models not allowing for eventual linear trends (Figure 1) or allowing for such trends (Figure 2). In each case, the number of lags in the auxiliary VARs was determined on the basis of the usual information criteria (Schwartz, Akaike, etc.). The VARs underlying the probabilities are stable and free of residual serial autocorrelation. 


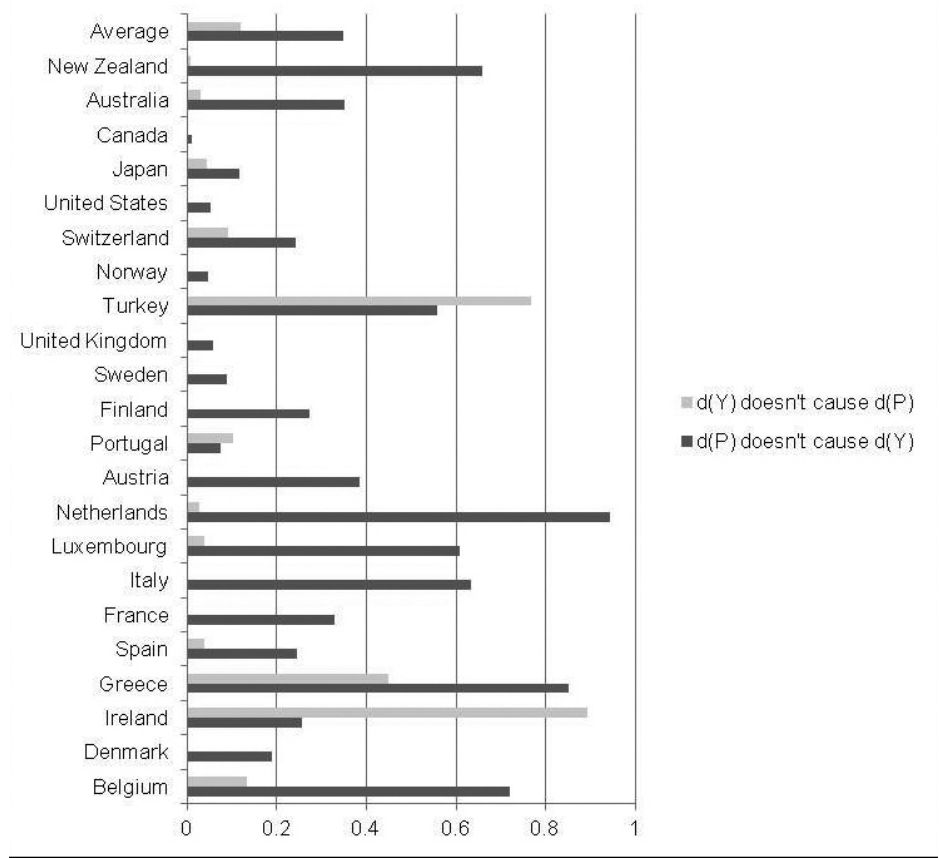

Figure 2. Probabilities of Granger non-causality (based on chi-sq stat.), allowing for linear trend, 1960-2015

directions: $d(P)$ Granger causes $d(Y)$ and $d(Y)$ Granger causes $d(P)$. There is no single case of causality running solely from $\mathrm{d}(\mathrm{P})$ to $\mathrm{d}(\mathrm{Y})$.

Even stronger results are obtained from auxiliary VARs allowing for eventual linear trends (Figure 2). In only 2 cases, there is statistical evidence of causality running from $d(P)$ to $d(Y)$, while the causality running from $d(Y)$ to $d(P)$ is confirmed in 16 cases.

Interestingly, in 15 cases, the causality running from $\mathrm{d}(\mathrm{Y})$ to $\mathrm{d}(\mathrm{P})$ is confirmed by both kinds of VARs (with and without the linear trends being allowed for). Such an overlap happens only in 2 cases of confirmed causality running from $\mathrm{d}(\mathrm{P})$ to $\mathrm{d}(\mathrm{Y})$.

The level of output determines (or Granger causes) the level of labour productivity much more often than otherwise

The testing of Granger causality applied to the rates of change of output and productivity $(\mathrm{d}(\mathrm{Y})$ and $\mathrm{d}(\mathrm{P})$, respectively) abstracts from the possibility that the responses presumed may depend on the absolute levels of Y and P. But it may be 


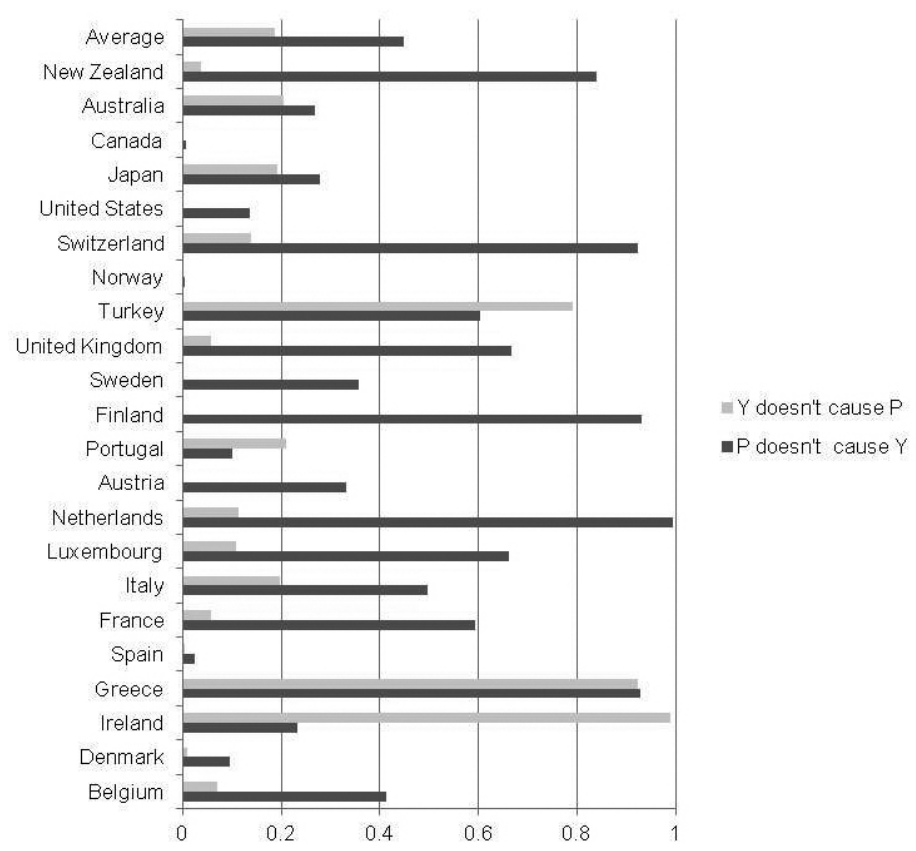

Figure 3. Probabilities of Granger non-causality (based on chi-sq stat.), 1960-2015

of interest to check whether the absolute level of one item is likely to be followed by the absolute level of the other item. In other words, it may be worthwhile checking whether Y "leads" $\mathrm{P}$, and whether $\mathrm{P}$ "leads" Y.

As the level variables $\mathrm{P}$ and $\mathrm{Y}$ are integrated of order 1 (thus nonstationary), the testing of the absence of Granger causality between them cannot - for "technical reasons" - proceed as suggested in Footnote 2. The proper procedure to apply here was developed by Toda - Yamamoto (1995). ${ }^{4}$ The results of testing following the application of the Toda-Yamamoto procedure are in Figures 3-4.

4 The Toda-Yamamoto procedure proceeds in steps. The first is the selection of the lag length (p) for the VAR (in levels, not in their first differences). The selection is guided by the information criteria (Schwartz, etc.) and the properties of the VAR (stability, absence of residual autocorrelation). The second step requires the determination of the order of integration of the original series considered (e.g. via ADF tests). Suppose the maximum of these orders is $\mathrm{m}$ (i.e. one of the series is integrated of order $\mathrm{m}$, the other is integrated of order not greater than $\mathrm{m}$ ). Third, the VAR (in levels) with $(\mathrm{p}+\mathrm{m})$ lags is estimated. Finally, one runs the standard Wald test that the coefficients of only the first $\mathrm{p}$ lagged values of $\mathrm{X}$ are zero in the equation for $\mathrm{Z}$ and does the same for the coefficients of the lagged values of $Z$ in the equation for $X$. Rejection of the null implies rejection of Granger non-causality (i.e. delivers evidence of Granger causality). The probabilities reported in Figures 3-4 were derived from the auxiliary VARs with $m=1$. 


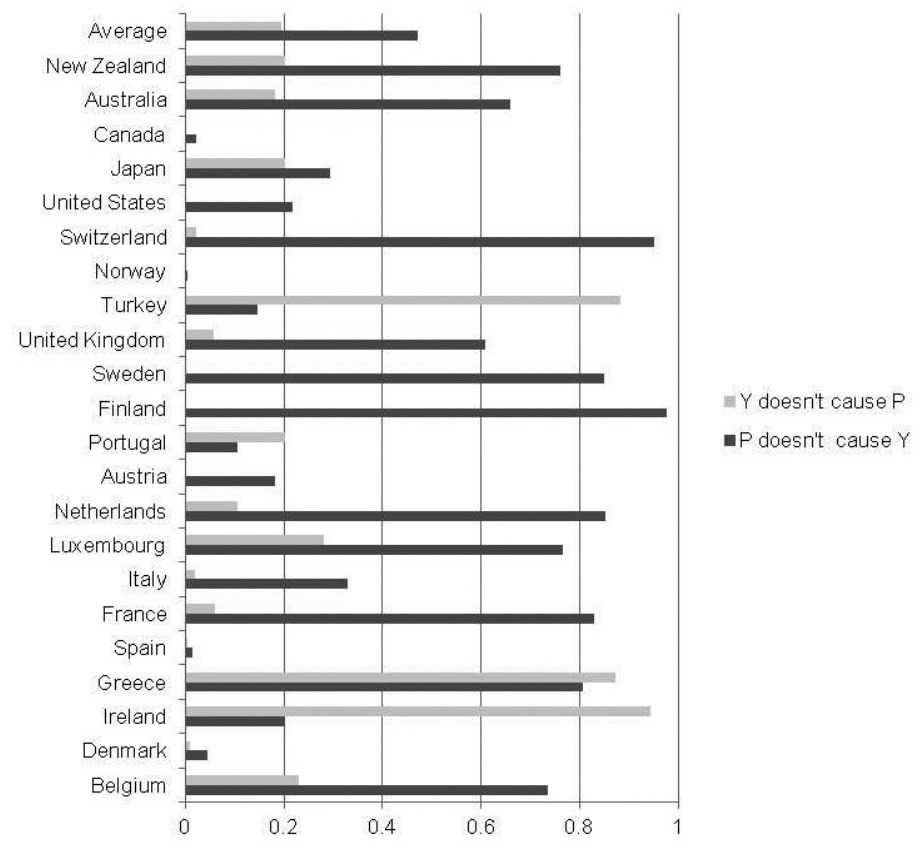

Figure 4. Probabilities of Granger non-causality (based on chi-sq stat.), allowing for linear trend, 1960-2015

As can be seen in Figure 3, the probabilities of Granger non-causality are, on average, much higher for the hypothesis on $\mathrm{P}$ affecting $\mathrm{Y}$ than for the hypothesis on $\mathrm{Y}$ affecting $\mathrm{P}$. The hypothesis on $\mathrm{P}$ not Granger causing $\mathrm{Y}$ is rejected, at the $5 \%$ significance level, in 3 cases. In these 3 cases, the statistical evidence is there on causality running from changes in productivity to changes in output. However, the hypothesis on Y not Granger causing P is rejected, at the 5\% significance level, in 9 cases. In these 9 cases, the statistical evidence is there on causality running from output to productivity. Output "leads" productivity much more often that productivity "leads" output.

Similar results are obtained from auxiliary VARs allowing for eventual linear trends (Figure 4). In only 4 cases is there statistical evidence of causality running from $\mathrm{P}$ to $\mathrm{Y}$, while the causality running from $\mathrm{Y}$ to $\mathrm{P}$ is confirmed in 10 cases.

Interestingly, in 8 cases, the causality running from $\mathrm{Y}$ to $\mathrm{P}$ is confirmed by both kinds of VARs (with and without linear trends being allowed for). Such an overlap happens only in 3 cases of confirmed causality running from P to Y. It may also be observed that the "mutual" Granger causation (simultaneously from $\mathrm{Y}$ to $\mathrm{P}$ and from $\mathrm{P}$ to $\mathrm{Y}$ ) is rather rare here (it is detected in Spain, Norway, and Canada). 


\section{Germany: No evidence on productivity affecting output growth}

The Y and P series for West Germany (1960-1991) and for unified Germany (1991-2015) are integrated of order 1, while their first differences are stationary. The results of testing of the Granger non-causality are summarised in Table 1. The probabilities in the upper panel of Table 1 are derived from auxiliary VARs (in differences), the probabilities in the lower panel are derived from auxiliary VARs in levels (following the application of the Toda-Yamamoto procedure).

As can be seen, the probabilities of Granger non-causality between the two items (whether differenced or not) are quite high for the unified Germany. In other words, neither does P Granger cause Y, nor does Y Granger cause P; neither does $d(P)$ Granger cause $d(Y)$, nor does $d(Y)$ Granger cause $d(P)$. In this respect, unified Germany resembles Ireland (but also Portugal and Greece). West Germany was, apparently, different. For that country, the evidence is strong that a change in output was followed by a change in productivity (with a change in productivity much less likely to have been followed by a change in output). In absolute terms, productivity did not "lead" output in that country - while output did "lead" productivity.

Table 1. Probabilities of Granger non-causality (based on chi sq stat.)

\begin{tabular}{l|c|c|c|c}
\hline & \multicolumn{2}{|c|}{ West Germany } & \multicolumn{2}{c}{$\begin{array}{c}\text { United Germany } \\
1969-1991\end{array}$} \\
\hline With trend in auxiliary VAR? & No & Yes & No & Yes \\
\hline $\mathrm{d}(\mathrm{Y})$ does not Granger cause d(P) & 0.0000 & 0.0006 & 0.1344 & 0.2723 \\
\hline $\mathrm{d}(\mathrm{P})$ does not Granger cause d(Y) & 0.0512 & 0.0839 & 0.7579 & 0.7099 \\
\hline Y does not Granger cause P & n.a. & 0.0013 & 0.6300 & 0.1611 \\
\hline P does not Granger cause Y & n.a. & 0.1234 & 0.8147 & 0.7522 \\
\hline
\end{tabular}

Note: n.a.: not available (aux. VAR unstable, autocorrelated residuals).

\section{Years 1991-2015: Findings not much different}

The economic environment has undergone immense changes since 1960. Also, the technological aspects of economic activities have been changing radically. Arguably, the conclusions derived from the data for the entire 1960-2015 period may no longer be valid for the post-1990 years (which have witnessed the ascent of neoliberal practices worldwide). Reassuringly, the findings concerning the incidence of Granger causality for the post-1990 years are not much different from those for the whole 1960-2015 period. The pattern of Granger causality (or noncausality) tends to be preserved. Most countries with Granger causality in some direction over the longer period exhibit the same characteristics over the shorter 
Table 2. Probabilities of Granger non-causality (based on chi sq stat.) for EU-15, 1991-2015

\begin{tabular}{l|c|c}
\hline With trend in auxiliary VAR? & No & Yes \\
\hline $\mathrm{d}(\mathrm{Y})$ doesn't cause $\mathrm{d}(\mathrm{P})$ & 0.6155 & 0.5377 \\
\hline $\mathrm{d}(\mathrm{P})$ doesn't cause $\mathrm{d}(\mathrm{Y})$ & 0.5977 & 0.7810 \\
\hline Y doesn't cause $\mathrm{P}$ & 0.6044 & n.a. \\
\hline P doesn't cause $\mathrm{Y}$ & 0.4034 & n.a. \\
\hline
\end{tabular}

Note: n.a.: not available (auxiliary VAR unstable/ AC residuals).

Table 3. Cases of rejection (at the 5\% significance level) of Granger non-causality for the 10 NMSs

\begin{tabular}{l|c|c}
\hline With trend in auxiliary VAR? & No & Yes \\
\hline $\mathrm{d}(\mathrm{Y})$ does not cause $\mathrm{d}(\mathrm{P})$ & Czech Rep. $(0.0433)$ & Poland $(0.0000)$ \\
\hline $\mathrm{d}(\mathrm{P})$ does not cause $\mathrm{d}(\mathrm{Y})$ & None & Slovenia $(0.0244)$ \\
\hline Y does not cause $\mathrm{P}$ & None & Polvia $(0.0246)$ \\
\hline & & Slovenia $(0.0000)$ \\
\hline P does not cause $\mathrm{Y}$ & & Poland $(0.0295)$ \\
\hline & Latvia $(0.0024)$ & Latvia $(0.0022)$ \\
\hline & & Slovenia $(0.0073)$ \\
\hline
\end{tabular}

Note: Probability of Granger non-causality in the bracket.

period. The composition of countries showing some Granger causality is remarkably stable (although in a few cases the critical probabilities slightly exceeding, or falling short of, the 5\% mark in one period are moved slightly below, or above, that mark in the other period).

For the years 1991-2015, AMECO provides time series on labour productivity and per capita GDP growth for the "old" European Union (aggregating the national data for its 15 West European MSs). As can be seen in Table 2, there is no Granger causality running in either direction for EU-15.

AMECO provides time series for the 10 NMSs. These series start in the early 1990s (at different dates for different NMS). It is advisable to disregard the data for the very early years (properly described as belonging to the "transformational recession" period). Also, the data for the late 1990s are not unproblematic. Nonetheless, it may make sense to check the eventual presence - and direction - of Granger causalities for these countries. Table 3 reports the cases of Granger causality suggested by the data for the 10 NMS $^{5}$ covering the years 1995-2015.

Bulgaria, Czech Republic, Estonia, Hungary, Latvia, Lithuania, Poland, Romania, Slovakia, and Slovenia. 
As can be seen, Granger causality running from $\mathrm{d}(\mathrm{Y})$ to $\mathrm{d}(\mathrm{P})$ can be detected in three countries: the Czech Republic, Poland, and Slovenia. Causality running from $\mathrm{d}(\mathrm{P})$ to $\mathrm{d}(\mathrm{Y})$ is detected only in Latvia. Granger-causality running from $\mathrm{P}$ to $\mathrm{Y}$ is detected in Latvia, Poland, and Slovenia. There is evidence on Granger causality running from $\mathrm{Y}$ to $\mathrm{P}$ in Poland and Slovenia. Absence of Granger causality running in either direction cannot be rejected in all remaining cases.

\section{CONCLUDING REMARKS}

The idea that labour productivity is affected (positively) by output growth is not quite novel. This is the essence of the classical Kaldor-Verdoorn Law (Verdoorn 1949; Kaldor 1966; McCombie et al. 2002). Our probability estimates suggest that in most cases output growth has been followed, in due course, by higher productivity - while productivity improvements have been much less likely to affect output growth. Thus, these estimates appear broadly consistent with the Law and not quite consistent with the conventional (and mainstream) convictions of productivity growth being the most essential determinant of economic growth.

A number of commentators and researchers have pondered on the ongoing productivity growth slowdown. Given the (apparent) acceleration of technological progress and the rather obvious advances in applied research and innovation activities, the labour productivity growth slowdown is considered a paradox. The solutions to the paradox sometimes forwarded suggest that output (and productivity) have been systematically underestimated by the statistics (e.g. Mokyr 2014 or Feldstein 2015). Others tend to disagree with the mismeasurement thesis without yet offering a coherent solution to the paradox (e.g. Byrne et al. 2016).

A simple explanation is implied by this paper. Namely, the growth of productivity is weakening because economic growth has been weakening secularly - since about the mid-1970s. But why has output growth been weakening secularly? That is a different question. The proposed answer to that question (Podkaminer 2014, 2015) points to the changes in the economic policy paradigms, not to any "adverse" technological developments. 


\section{REFERENCES}

Byrne, D. - Fernald, J. G. - Reinsdorf, M. B. (2016): Does the United States Have a Productivity Slowdown or a Measurement Problem? Brookings Papers on Economic Activity, Conference Draft, March 10-11.

Canuto, O. - Nallari, R. - Griffith, B. (2014): Sluggish Post-Crisis Growth: Policies, Secular Stagnation and Outlook. Economic Premise, No. 139. World Bank.

Feldstein, M. (2015): The U.S. Underestimates Growth. Wall Street Journal, 18 May.

Gordon, J. R. (2015): Secular Stagnation: A Supply-Side View. American Economic Review: Papers \& Proceedings, 105(5): 54-59.

Kaldor, N. (1966): Causes of the Slow Rate of Economic Growth in the United Kingdom. Cambridge: Cambridge University Press.

McCombie, J. S. L. - Pugno, M. - Soro, B. (eds) (2002): Productivity Growth and Economic Performance. Palgrave Macmillan.

Mokyr, J. (2014): Secular Stagnation? Not in Your Life. In: Teulings, C. - Baldwin, R. (eds): Secular Stagnation: Facts, Causes, and Cures. VoxEU.org eBook.

Podkaminer, L. (2014): Does Trade Drive Global Growth? Bank \& Credit, 45(4): 311-330.

Podkaminer, L. (2015): The Euro Area's Secular Stagnation and What can be Done about It. A PostKeynesian Perspective. Real World Economics Review, 70:1-15.

Teulings, C. - Baldwin, R. (eds) (2014): Secular Stagnation: Facts, Causes, and Cures. VoxEU. org eBook.

Toda, H. Y. - Yamamoto, T. (1995): Statistical Inference in Vector Autoregressions with Possibly Integrated Processes. Journal of Econometrics, 66(1-2): 225-250.

Verdoorn, P. J. (1949): Fattori che regolamo lo sviluppo della produttività del lavoro (On the Factors Determining the Growth of Labor Productivity). L'Industria, 1: 3-10.

Yellen, J. (2015): Speech delivered at the Philadelphia Fed Policy Forum, https://www.federalreserve. gov/newsevents(speech/yellen/20150711a.htm 